\title{
Spontaneous Spinal Epidural Hematomas: Case Series with Review of Literature
}

\author{
Authors \\ Azher Maqbool Khan ${ }^{1}$, Obaid Ashraf ${ }^{2}$, Zubair Ahmad $^{3}$, Tahleel Altaf Shera ${ }^{4}$, \\ Ghulam Muhammad Wani ${ }^{5}$, Naseer Ahmad Choh $^{6}$, Feroze Ahmad Shaheen ${ }^{7}$ \\ Tariq Gojwari $^{8}$, Irfan Robbani ${ }^{9}$
}

${ }^{1,9}$ Department of Radiology, Sher-I-Kashmir Institute of Medical Sciences, Srinagar, Jammu and Kashmir Corresponding Author

Obaid Ashraf

Department of Radiology, Sher-I-Kashmir Institute of Medical Sciences, Srinagar, Jammu and Kashmir Email: obaid020@yahoo.in

\begin{abstract}
Spontaneous spinal epidural hematoma $(E D H)$ is a relatively rare condition that requires urgent diagnosis and management. Such patients typically present with acute and severe back pain and spinal cord or caudaequina compression. Risk factors include coagulopathy, anticoagulation, vascular anomalies, inter vertebral disk herniation, Paget disease of bone, Valsalva maneuver and hypertension. Differential diagnosis includes an acute herniated inter vertebral disc, acute ischemia of the spinal cord, epidural tumor or abscess, spondylitis, transverse myelitis, or even a dissecting aortic aneurysm and acute myocardial infarction.An observational study was conducted in the Department of Radiodiagnosis, SKIMS Srinagar to study the clinical features, imaging features and treatment outcomes of spontaneous spinal epidural hematomas.This study shows that MR Imaging is a very sensitive and specific modality for diagnosis of spontaneous epidural hematomas. Also early management in the form of early decompressive laminectomy and hematoma evacuation is helpful in preventing permanent neuro deficit.

Keywords: Epidural hematoma, MRI, Spinal epidural space.
\end{abstract}

\section{INTRODUCTION}

Spontaneous spinal epidural hematoma $(\mathrm{EDH})$ is a relatively rare condition that requires urgent diagnosis and management ${ }^{(1-4)}$. Such patients typically present with acute and severe back pain and rapidly developing signs of spinal cord or caudaequina compression ${ }^{(5)}$.

Such spontaneous spinal EDHs have been attributed most commonly to a venous source ${ }^{(5-7)}$. Some of the risk factors include coagulopathy, anticoagulation, vascular anomalies, inter vertebral disk herniation, Paget disease of bone, Valsalva maneuver, and, in some cases, hypertension ${ }^{(1,5,8-13)}$.

\section{MATERIALS AND METHODS}

The study was conducted in the Department of Radiodiagnosis, SKIMS Srinagar. Seven patients were included in the study and MR Imaging was done using Siemens Magnetom Avanto 1.5 Tesla scanner (Siemens Medical Systems, Germany). 


\section{JMSCR Vol||05||Issue||07||Page 25728-25735||July}

\section{Clinical profile}

Four of our patients were male and three female (M:F ratio 1.3:1). The age of the patients ranged from 19 to 74 years with a mean age of 49 years. Two of our patients had risk factors for hemorrhage, both were on antiplatelet drugs. Three of our patients had back pain, while four of them presented with weakness (three with paraparesis and two with quadriparesis). One patient presented with an additional complaint of altered sensorium (from a concomitant cerebral SDH). The time that elapsed from symptom onset to imaging varied from 18 hours to 216 hours ( 9 days), with an average time of 109 hours (4.5 days). Two of our patients had extradural hematomas in cervical region, three in dorsal and one in lumbar region. One patient had a dorsolumbar hematoma. The mass effect of the hematoma in the form cord compression and myelopathy (T2W and STIR hyperintensity) was mild, moderate or severe in two patients each. Two patients were managed conservatively while the rest five underwent laminectomy for decompression and hematoma evacuation. One patient who had a concomitant spontaneous cerebral SDH also underwent burrhole drainage of the same. Postoperative follow up showed improvement in the presenting clinical symptoms of most patients, complete resolution in four, minimal residual weakness in one, moderate residual weakness in one while one patient expired in the immediate postoperative period.

\section{IMAGING FEATURES}

The imaging sequences used in our patients were saggital and axial T1W, T2W images of the involved regions. Additional sequences in saggital plane were acquired in selected cases (STIR, Fat suppressed T1W, post contrast T1W FS).

The signal characteristics of the hematomas varied as a function of time from symptom onset to imaging, consistent with the signal characteristics of blood degradation products at different stages.

Hematomas in two patients were characterized as hyperacute based on their isointense signal on T1WI and mixed to hyperintense on T2WI. Both these patients were imaged in less than 24 hours from symptom onset. Two of the patients had early subacute hematomas characterized by hyperintense signal on T1WI and hypointensity on T2WI. The time from symptom onset to imaging varied from 2 to 3 days in these two patients. Three patients had late subacute hematomas which were characterized by hyperintense signal on both $\mathrm{T} 1 \mathrm{~W}$ and $\mathrm{T} 2 \mathrm{~W}$ images.

Table. No 1 Clinical features

\begin{tabular}{|c|c|c|c|c|c|c|c|c|c|c|}
\hline \multirow{3}{*}{$\begin{array}{l}\text { Case } \\
\text { num } \\
\text { ber }\end{array}$} & \multirow{3}{*}{$\begin{array}{c}\text { Time from } \\
\text { symptom } \\
\text { onset }\end{array}$} & \multirow[t]{3}{*}{ Extent } & \multicolumn{7}{|c|}{ Imaging Features } & \multirow{3}{*}{$\begin{array}{c}\text { Cord } \\
\text { compres } \\
\text { sion } \\
\end{array}$} \\
\hline & & & \multicolumn{2}{|c|}{ T1W } & \multicolumn{2}{|c|}{ T2W } & \multirow[t]{2}{*}{ Rad stage } & \multirow[t]{2}{*}{ Gd+ } & \multirow[t]{2}{*}{ Others } & \\
\hline & & & $\begin{array}{l}\text { Perip } \\
\text { hery }\end{array}$ & Centre & $\begin{array}{l}\text { Periphe } \\
\text { ry }\end{array}$ & Centre & & & & \\
\hline 1 & 3 days & $\begin{array}{l}\text { D3- } \\
\text { D10 }\end{array}$ & $\uparrow$ & $\leftrightarrow$ & $\downarrow$ & $\downarrow$ & Early subacute & NA & $\overline{\mathrm{T} 1 \mathrm{WFS} \uparrow}$ & + \\
\hline 2 & 18 hours & $\mathrm{C} 5-\mathrm{C} 7$ & $\leftrightarrow$ & $\leftrightarrow$ & $\uparrow \downarrow$ & $\uparrow \downarrow$ & Hyperacute & NA & NA & +++ \\
\hline 3 & 24 hours & D6-D9 & $\leftrightarrow$ & $\leftrightarrow$ & $\uparrow$ & $\uparrow$ & Hyperacute & NA & NA & ++ \\
\hline 4 & 8 days & D6-L5 & $\uparrow$ & $\uparrow$ & $\uparrow$ & $\uparrow$ & Late subacute & $\begin{array}{c}\text { No } \\
\text { enhance } \\
\text { ment }\end{array}$ & $\begin{array}{l}\text { Brain } \\
\text { SDH+ }\end{array}$ & + \\
\hline 5 & 2 days & C4-T1 & $\uparrow$ & $\uparrow$ & $\downarrow$ & $\downarrow$ & Early subacute & NA & NA & +++ \\
\hline 6 & 9 days & $\begin{array}{l}\text { D10- } \\
\text { L1 }\end{array}$ & $\uparrow$ & $\uparrow$ & $\uparrow$ & $\uparrow$ & Late subacute & NA & $\mathrm{NA}$ & ++ \\
\hline 7 & 8 days & L2-L5 & $\uparrow$ & $\uparrow$ & $\uparrow$ & $\uparrow$ & Late subacute & NA & NA & - \\
\hline
\end{tabular}




\section{JMSCR Vol||05||Issue||07||Page 25728-25735||July}

Table. No 2 Imaging features

\begin{tabular}{|c|c|c|c|c|c|}
\hline $\begin{array}{l}\text { Case } \\
\text { number }\end{array}$ & Age/Sex & Risk Factors & Clinical Features & Treatment & Clinical outcome \\
\hline 1 & $45 / \mathrm{F}$ & None & Back pain & Conservative & Pain resolved \\
\hline 2 & $62 / \mathrm{M}$ & None & Quadriparesis & Laminectomy & Minimal residual deficit \\
\hline 3 & $19 / \mathrm{M}$ & None & $\begin{array}{c}\text { Back pain, lower limb } \\
\text { weakness }\end{array}$ & Laminectomy & No residual deficit \\
\hline 4 & 64/M & $\begin{array}{c}\text { Coagulopath } \\
y\end{array}$ & $\begin{array}{l}\text { Altered sensorium, } \\
\text { Lower limb weakness }\end{array}$ & $\begin{array}{l}\text { Laminectomy+burr hole } \\
\text { drainage of cerebral SDH }\end{array}$ & Expired \\
\hline 5 & $74 / \mathrm{M}$ & None & Quadriparesis & Laminectomy & Moderate residual deficit \\
\hline 6 & $35 / \mathrm{F}$ & None & Paraparesis & Laminectomy & No residual deficit \\
\hline 7 & $44 / \mathrm{F}$ & $\begin{array}{c}\text { Coagulopath } \\
y\end{array}$ & LBA & Conservative & Pain resolved \\
\hline
\end{tabular}

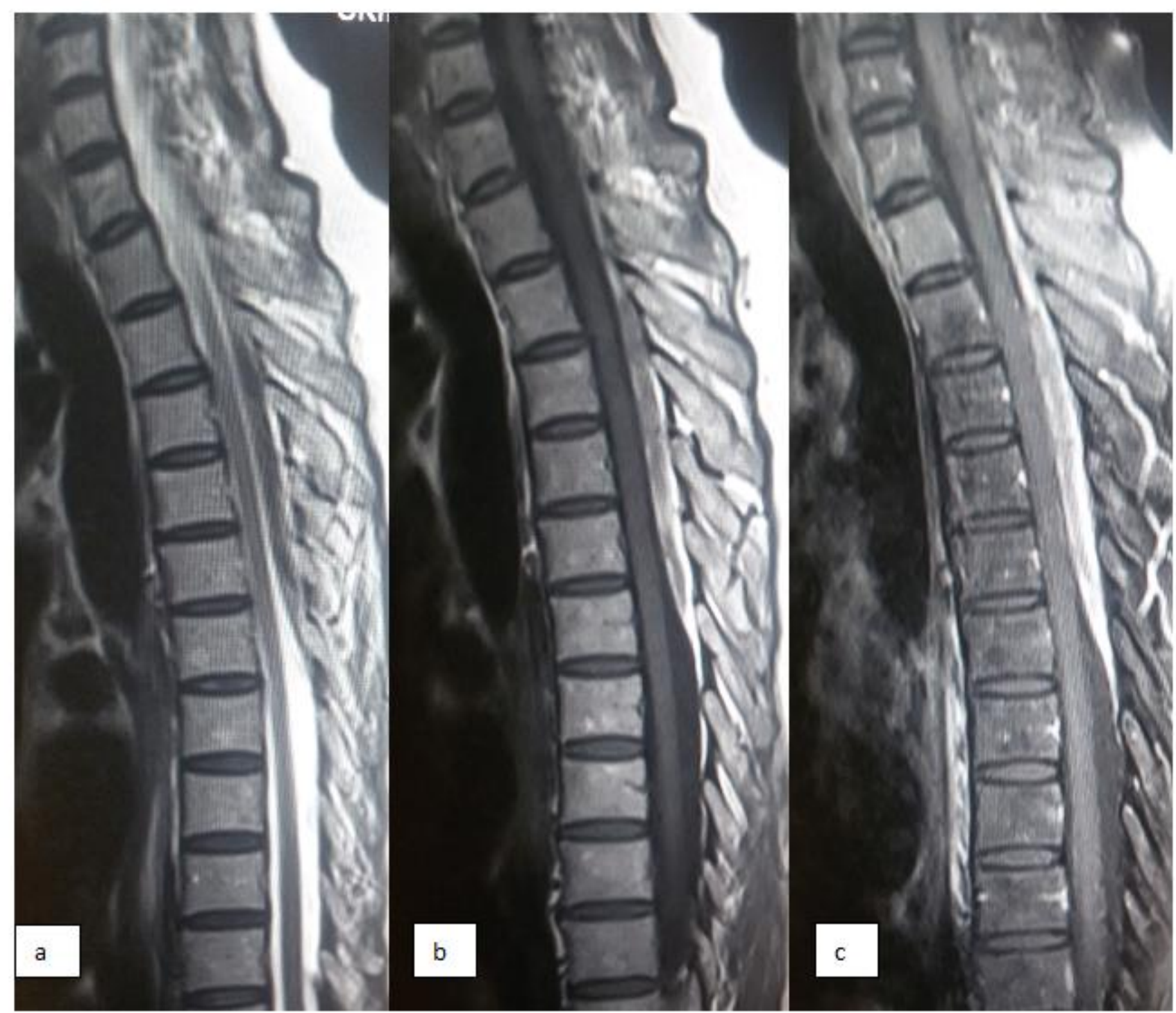

Figure 1: Sagittal T2-weighted (a), T1-weighted (b) and fat saturated T1-weighted (c) MR Images in a patient with spontaneous spinal epidural hematoma involving the dorsal epidural space. No significant cord compression is seen. 


\section{JMSCR Vol||05||Issue||07||Page 25728-25735||July}

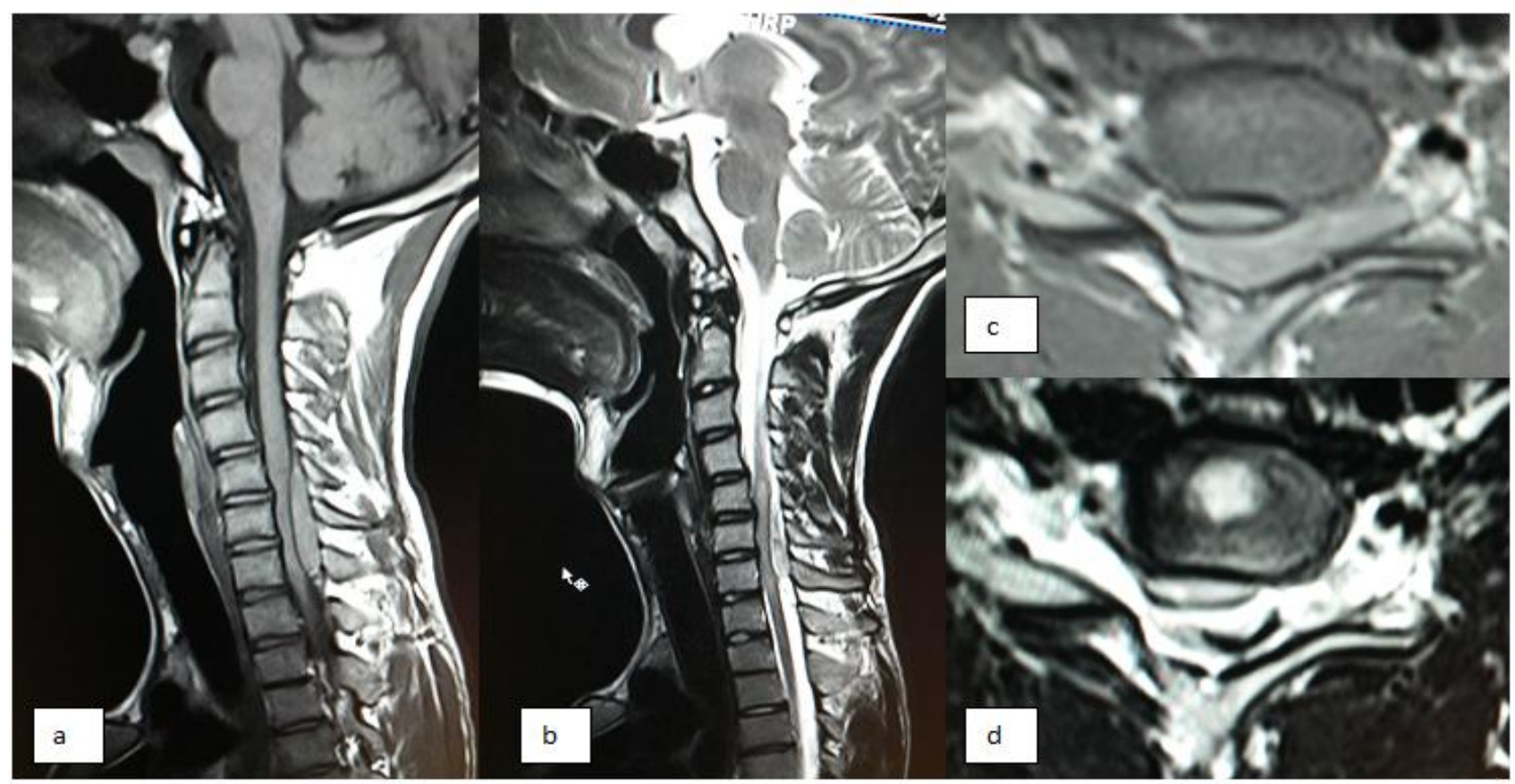

Figure 2: SaggitalT1-weighted (a), T2-weighted (b), axial T1-weighted (c) and axial T2-weighted (d) images show a small cervical epidural hematoma causing moderate cord compression and T2-weighted cord hyperintensity suggestive of cord edema.

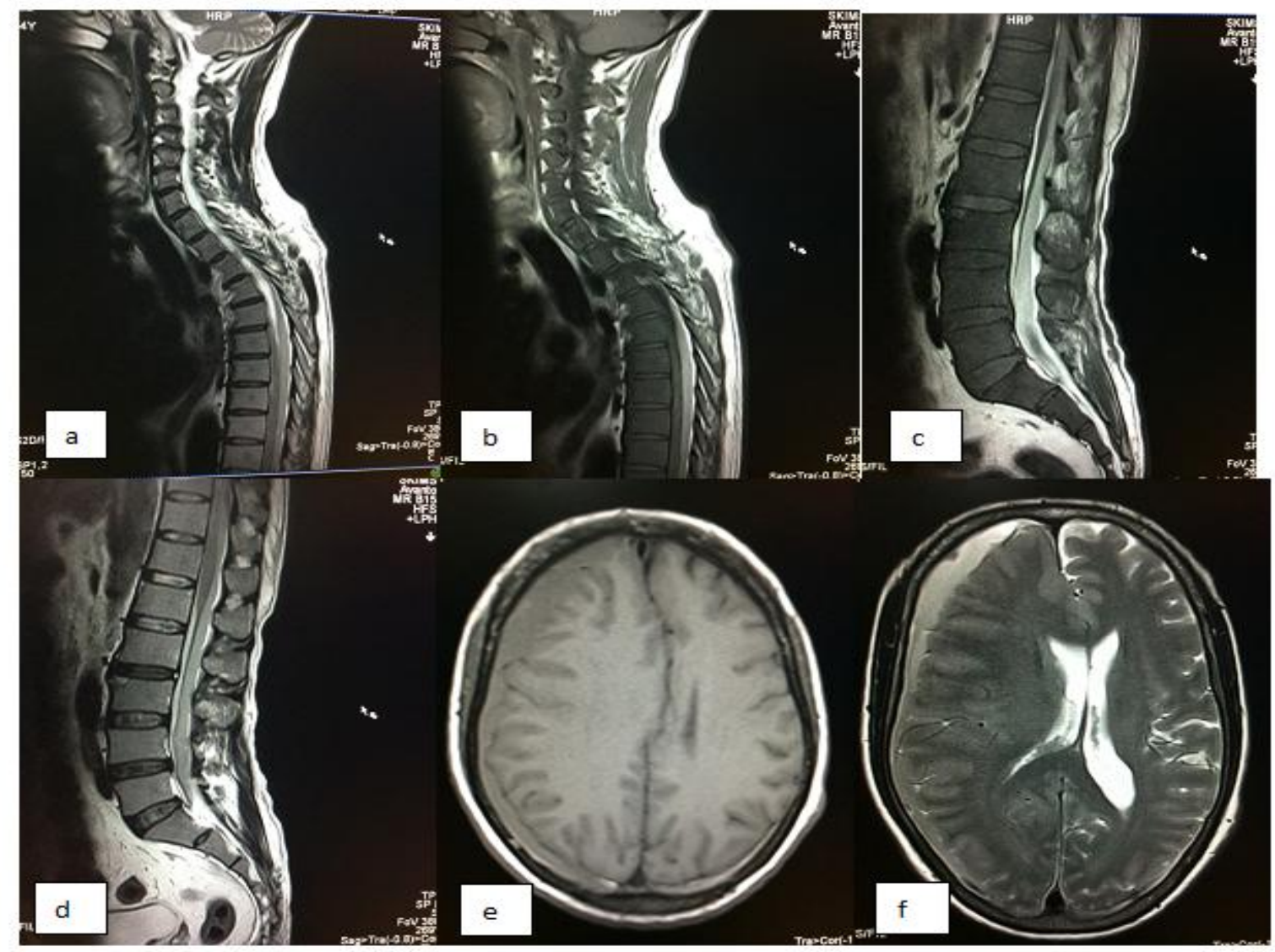

Figure 3: Spontaneous spinal EDH in a patient with coagulopathy. Sagittal T2-weighted (a), T1-weighted (b) images of the cervical spine and saggital T2-weighted (c) and T1-weighted (d) images of lumbar spine show an extensive subacute hematoma in dorsolumbar region. The patient also had a spontaneous concomitant brain SDH as seen on T2W (e) and T1W (f) axial images of brain. 


\section{DISCUSSION}

Spontaneous spinal epidural hematoma (SSEH) is a relatively rare disease. Its incidence as estimated by Holtas et al was 0.1 per 100,000 people ${ }^{(14)}$.

\section{Epidemiology}

Spontaneous spinal epidural hematomas are most frequent in the fourth or fifth decade of life ${ }^{(15)}$. Its occurrence has been noted in all age groups, however it is a very rarely encountered in children. There are only about 30 pediatric cases of SSEH documented in the medical literature. The male/female ratio is $1.4: 17^{(16,17)}$.

\section{Etiology}

Many known precipitating factors, include systemic therapeutic anticoagulant for a variety of diseases, thrombolysis for acute myocardial infarction, vascular malformation, hemophilia $\mathrm{B}$, factor XI deficiency, long-term antiplatelet drug use ${ }^{(18,19)}$.

The origin of these SEDHs has been a point of debate. Most investigators suggest that SSEHs originate from the epidural venous plexus in the spinal epidural space because of the absence of venous valves. Therefore the fluctuating pressure from the thoracic and abdominal cavities can influence it directly ${ }^{(15,20,21)}$. Few authors have suggested that spinal epidural arteries may be a source of hemorrhage ${ }^{(19)}$.

\section{Clinical features}

The two most frequent locations of a spontaneous spinal epidural hematoma is the cervicothoracic region, followed by thoracolumbar region ${ }^{(15,22)}$.

Usually, patients present with sudden onset and stabbing neck or back pain which leads to paraparesis or quadriparesis, depending on the level of the hematoma ${ }^{(23)}$. Symptoms in children may include $\mathrm{s}$ of irritability, and occasionally urinary retention ${ }^{(16)}$. In high cervical region, SSEHs could represent a potentially fatal condition from spinal shock $^{(14)}$.

\section{Imaging}

At present, MRI is considered as the imaging modality of choice for SSEH as has been documented by many authors ${ }^{(28-32)}$. The advantages include information about the extent and nature of the hematoma, degree of cord compression. It is also very helpful in guiding treatment, because of its non-invasive nature and lack of ionizing radiation and examinations can be repeated often in those being managed conservatively ${ }^{(1)}$.

Characteristic features at MR imaging is a biconvex hematomas in the epidural space showing welldefined borders that taper superiorly and inferiorly. Subacute hematomas show characteristic high signal intensity on T1-weighted images ${ }^{(33)}$. A CT scan should be obtained if MRI is unavailable ${ }^{(21)}$.

Gundry and Heithoff ${ }^{(10)}$ in a series of 18 surgically confirmed cases of lumbar EDH, described the signal characteristics of spinal EDH after an average of 169 days on T2WI but did not discuss T1weighted imaging signal characteristics. Subacute and chronic spinal EDH have usually been described as hyperintense $\mathrm{e}^{(1,11,12,30,31,34,35,36,37)}$, and less often as isointense ${ }^{(1,31,34)}$, to the spinal cord on T1-weighted images.

In a series of three cases of spontaneous spinal EDH within 48 and 72 hours, Rothfus et al ${ }^{(31)}$ described the MR signal characteristics. Findings on T1weighted images were described as hyperintense in one, isointense in one, and heterogeneous in one.

Holtas et al ${ }^{(1)}$ studied 13 patients of spinal EDH at 0.3 and $1.5 \mathrm{~T}$ and reported their signal characteristics as isointense on T1- weighted images in only two of six cases imaged within 2 days after symptoms onset. The authors suggested that T1 weighted MR images were most valuable because of the signal shift from isointensity with the cord in the early period to hyperintensity in the intermediate stage.

Fukui et al reported the signal characteristics of acute spinal EDH. They observed focal hypointense foci within the primarily hyperintense extra axial collection on T2- weighted spin-echo or gradientecho images. These could represent deoxyhemoglobin or the fibrous septa attaching the dura to the bony spinal canal. They concluded that T2weighted pulse sequences added important diagnostic information at the time of presentation of spinal EDH when characteristic hyperintensity is usually lacking on T1-weighted images ${ }^{(38)}$. 


\section{Differential diagnosis}

The differential diagnosis of spontaneous spinal epidural hematoma includes an acute herniated intervertebral disc, acute ischemia of the spinal cord, epidural tumor or abscess, spondylitis, transverse myelitis, or even a dissecting aortic aneurysm and acute myocardial infarction ${ }^{(39)}$.

\section{Management}

Early surgical treatment is usual for spontaneous spinal epidural hematomas ${ }^{(40)}$. Decompressive laminectomy and hematoma removal is usually done. The dura should be opened to exclude a subdural hematoma in case the exact location of the hematoma is uncertain on imaging. It is recommended that the surgery should be performed within 48 hours of the onset of the initial symptoms if the neurodeficit is incomplete. If neuro deficit is complete, the surgery should be performed within 36 hours ${ }^{(20)}$. It has been recommended by many authors that early decompressive surgery should be performed before interference with blood supply to the cord occurs and in such cases the prognosis is favorable ${ }^{(2-4)}$. There are increasing reports describing the resolution of spinal EDH with nonoperative management $(1,9,30,35,41,42,43)$. Conservative treatment has been employed only when neurological deficits improved in the early phase or with the coexistence of coagulopathy ${ }^{(17)}$. In patients with coagulopathy, multilevel epidural hematomas are difficult to treat surgically ${ }^{(27)}$. These patients may not make a complete functional recovery, but there are no associated surgical risks (17)

\section{CONCLUSIONS}

This study shows that MR Imaging is a very sensitive and specific modality for diagnosis of spontaneous epidural hematomas. Also early management in the form of early decompressive laminectomy and hematoma evacuation is helpful in preventing permanent neuro deficit.

\section{REFERENCES}

1. Holtas S, Heiling $M$, Lonntoft $M$. Spontaneous spinal epidural hematoma.
Findings at MR imaging and clinical correlation. Radiology 1996;199:409-433

2. Foo D, Rossier A. Preoperative neurological status in predicting surgical outcome of spinal epidural hematomas. SurgNeurol 1981;15:389-401

3. McQuarrie G. Recovery from paraplegia caused by spontaneous spinal epidural hematoma. Neurology 1978;28:224-228

4. Packer N, Cummins B. Spontaneous epidural hemorrhage. A surgical emergency. Lancet 1978;1:356-358

5. Groen R, Ponssen H. The spontaneous spinal epidural hematoma.A study of the etiology. J NeurolSci 1990;98:121-138

6. Groen RJ, Groenewegen HJ, van Alphen HA, Hoogland PV. Morphology of the human internal vertebral venous plexus.A cadaver study after intravenous Araldite CY 221 injection.Anat Rec 1997;249:285-294

7. Joseph AP, Vinen JD. Acute spinal epidural hematoma. J Emerg Med 1993;11:437-441

8. Lee K, McWhorter J, Angelo J. Spinal epidural hematoma associated with Paget's disease. SurgNeurol 1988;30:131-134

9. Brawn L, Bergval U, Davies-Jones G. Spontaneous spinal epidural haematoma with spontaneous resolution. Postgrad Med J 1981;62:885-887

10. Gundry C, Heithoff K. Epidural hematoma of the lumbar spine. 18 surgically confirmed cases. Radiology 1993;187:427-431

11. Caldemeyer K, Mocharla R, Moran C, Smith R. Gadolinium enhancement in the center of a spinal epidural hematoma in a hemophiliac. J Comput Assist Tomogr 1993;17:321-323

12. Muhonen M, Piper J, Moore S, Menezes A. Cervical epidural hematoma secondary to an extradural vascular malformation in an infant. Case report. Neurosurgery 1995; 36:585-588

13. David S, Salluzzo RF, Bartfield JM, Dickinson ET. Spontaneous cervicothoracic epidural hematoma following prolonged 
Valsalva secondary to trumpet playing. Am J Emerg Med 1997;15: 73-75

14. Chan DT, Boet R, Poon WS, Yap F, Chan YL : Spinal shock in spontaneous cervical spinal epidural haematoma. ActaNeurochir (Wien) $146:$ 161-1162; discussion 11621163, 2004

15. Guzel A, Simsek O, Karasalihoglu S, Kucukugurluoglu Y, Acunas B, Tosun A, et al : Spontaneous spinal epidural hematoma after seizure : a case report. ClinPediatr46 : 263-265, 2007

16. Poonai N, Rieder MJ, Ranger A : Spontaneous spinal epidural hematoma in an 11-month-old girl. PediatrNeurosurg43 : 121- 124, 2007

17. Tailor J, Dunn IF, Smith E : Conservative treatment of spontaneous spinal epidural hematoma associated with oral anticoagulant therapy in a child. Childs NervSyst22 : 1643-1645, 2006

18. Bisson EF, Dumont T, TranmerB : Spontaneous Spinal Epidural Hematoma in a Child with Hemophilia B. Can J NeurolSci34 : 488-490, 2007

19. Solheim O, Jorgensen JV, NygaardOP : Lumbar epidural hematoma after chiropractic manipulation for lower back pain : Case Report. Neurosurgery 61 : E170171; discussion E171, 2007

20. Liu Z, Jiao Q, Xu J, Wang X, Li S, You C: Spontaneous spinal epidural hematoma: analysis of 23 cases. SurgNeurol69 : 253260; discussion 260, 2008

21. Riaz S, Jiang H, Fox R, Lavoie $M$, MahoodJK : Spontaneous spinal epidural hematoma causing Brown-Sequard syndrome : case report and review of the literature. J Emerg Med 33 : 241-244, 2007

22. Shin JJ, Kuh SU, Cho YE : Surgical management of spontaneous spinal epidural hematoma. Eur spine J 15 : 998-1004, 2006

23. Hangping Y, Shunwu F, Huilin Y, Tiansi T, Feng Z, Xing Z : Early diagnosis and treatment of acute or subacute spinal epidural hematoma. Chin Med J 120 : 13031308, 2007

24. Bose S, Ali Z, Rath GP, PrabhakarH : Spontaneous spinal epidural hematoma : a rare cause of quadriplegia in the post-partum period. Br J Anaesth99 : 855-857, 2007

25. Park J, Lee JB, Park JY, Lim DJ, Kim SD, Chung YK : Spinal cord infarction after decompressive laminectomy for spontaneous spinal epidural hematoma. Neurol Med Chir (Tokyo) $47:$ 325-327, 2007

26. Song KJ, Lee KB : The poor outcome of the delayed diagnosis of acute spontaneous spinal epidural hematoma : two cases report. J Korean Med Sci20 : 331-334, 2005

27. Ziyal IM, Aydin S, Inci S, Sahn A, OzagenT : Multilevel acute spinal epidural hematoma in a patient with chronic renal failure- case report. Neurol Med Chir (Tokyo) 43 : 409412, 2003

28. Gundry CR, Heithoft KB. Epidural herna.toniii Of the lunibar spine: 18 surgically confirmed cast's. Radiology 1993; 187:427- 431.

29. D’Angebo, Bizzozero L, Tabamonti C, Ferrara M, Cobombo N. Value of magnetic resona $0 \mathrm{CC}$ imaging in spontaneous extradurab spinal hematoma due' to vascular malformation (case report). SurgNe'urob 1990; 34:343-344.

30. Saito S, Katsuhe H, Kohayashi Y. Spinal e'pidurab hematoma with spontaneous recovery demonstrated by magnetic resonance' imaging. Spine 1994;19:483-486.

31. Rothfus WE, Chedid MK, Deeb ZL, Abla AA, Maroon JC, Sherman RL. MR imaging in the diagnosis of spontaneous spinal epidurab hematomas.J Comput Assist Tomogr 1987; 11:851-854.

32. Donovan Post MJ, Becerra JL, Madsen PW, et $\mathrm{ab}$. Acute spinal subdurab hematoma: MR and CT findings with pathologic correbates. AJNR 1994; 15:1895-1905.

33. Fujiwara H, Oki K, Momoshima S, Kuribayashi $S$ : PROPELLER diffusion- 
weighted magnetic resonanace imaging of acute spinal epidural hematoma. ActaRadiol46 : 539-542, 2005

34. Avrahami E, Tadmor R, Ram Z, Feibel M, Itzhak Y. MR demonstration of spontaneous acute epidural hematoma of the thoracic spine. Neuroradiology 1989;31:89-92

35. Bernsen P, Haan J, Vielvoye G, Peerlinck K. Spinal epidural hematoma visualized by magnetic resonance imaging. Neuroradiology 1988;30:280

36. Crisi G, Sorgato P, Colombo A, Scarpa M, Falasca A, Angiari P. Gadolinium-DTPAenhanced MR imaging in the diagnosis of spinal epidural haematoma. Report of a case. Neuroradiology 1990;32:64-66

37. Latham J, Dracopoulos G, Hall D. Cervical epidural haematoma following minor trauma. Aust NZ J Surg 1993;63:985-986

38. Melanie B. Fukui, Amar S. Swarnkar and Robert L. Williams. American Journal of Neuroradiology July 1999, 20 (7) 13651372;

39. Byung Suck Baek, M.D., Jin Woo Hur, M.D.,corresponding author Ki Young Kwon, M.D., and Hyun Koo Lee, M.D. J Korean Neurosurg Soc. 2008 Jul; 44(1): 40-42.

40. Matsumura A, Namikawa T, Hashimoto R, Okamoto T, Yanagida I, Hoshi M, et al : Clinical management for spontaneous epidural hematoma : diagnosis and treatment. Spine J 8 : 534-537, 2007

41. Harik S, Raichle M, Reis DJ. Spontaneously remitting spinal epidural hematoma in a patient on anticoagulants. N Engl J Med 1971;284:1355-1357

42. Hernandez D, Vinuela F, Feasby T. Recurrent paraplegia with total recovery from spontaneous spinal epidural hematoma. Ann Neurol 1982;11:623-624

43. Priest W. Epidural hemorrhage due to hemophilia. Lancet 1935; 2:1289-1291. 